\title{
EDITORIAL
}

\section{REFLEXIONES AL PROYECTO DE REFORMA DE LA EDUCACIÓN SUPERIOR EN COLOMBIA}

\author{
Germán Anzola Montero \\ Rector
}

La experiencia de 45 años vinculada al quehacer universitario, me permite, con ocasión del proyecto de reforma a la Educación Superior, dejar a consideración de los lectores de esta publicación, una serie de reflexiones, que bien vale la pena tener en cuenta.

Con el Decreto Ley 80 de 1980, uno podría afirmar que se constituyó en la normativa que permitió, hasta hoy, organizar el conjunto de instituciones que, de acuerdo con este Decreto Ley, habrían de constituir la modalidad de la educación post-secundaria que, hasta ese momento, no disponía de ninguna organización, ni regulación y, mucho menos, de controles adecuados para garantizarle a la Educación Superior no solo la calidad y la excelencia que le corresponde a este nivel sino el desempeño de la misma dentro de los más altos y exigentes criterios e indicadores de responsabilidad social universitaria, ante sus beneficiarios. Adicional a este primer planteamiento, se consagraron principios fundamentales, que permitieron definir la Educación Superior como un servicio público de carácter cultural, ofrecido por instituciones de naturaleza pública y privada, señalando, para esta última, la no búsqueda de lucro a partir de su ofrecimiento.

Otros hechos de recordación, consagrados en el Decreto Ley 80 , fueron la posibilidad de ofrecer programas por ciclos de formación (técnica, tecnológica y universitaria), desconociendo una tradición de valoración académica (créditos académicos), por un improvisado e inaplicable concepto de las Unidades de Labor Académica -ULAS, es decir, que 12 años se perdieron, perjudicando los tan importantes procesos de planeación académica $y$, además, para no desnaturalizar la tarea, siempre arrogante, del Estado colombiano es el gobierno de turno, se ratificó el concepto de la SAGRADA INSPECCIÓN Y VIGILANCIA del mismo, frente a las Instituciones de Educación Superior. Hoy, por más de 30 años, se ha demostrado que este tipo de control ha sido inútil para contener las irresponsabilidades y los abusos que suelen cometer, una minoría de instituciones, que quieren ver la Educación Superior como una fuente o posibilidad impropia e inadecuada de enriquecimiento, a partir del derecho o bien social, que les corresponde al recibir su Educación Superior.

Con fundamento en la nueva Constitución Política de 1991 fue determinante reglamentar lo concerniente a la Educación Superior, la cual, se realizó con la promulgación de la Ley 30 de 1992, cuyo principal criterio de inspiración correspondió a la consagración de la AUTONOMÍA UNIVERSITARIA, expresada en el Artículo 67 de la Carta Magna de Colombia, pero equivocadamente desarrollada, ocasionando un costo muy negativo para la universidad colombiana y una confusión total para el supuesto sistema de educación superior, ya que no es posible generalizar, por ningún motivo, el concepto de autonomía universitaria hacia aquellas instituciones que no son universidades. Este hecho, es una de las principales razones que afectan la calidad académica, que debe predominar en cualquier nivel educativo, pues bajo el hipotético derecho de una serie de libertades, no ha sido ni es altamente responsable en la prestación de este servicio educativo.

Con la aprobación de las tipologías para las instituciones, bajo la Ley 30 , y sin resultados positivos frente a su control, fue necesario ratificar el concepto de la Constitución Política, inspección y vigilancia, suscitando, por fin, en el panorama nacional, un esquema de trabajo, favoreciendo los criterios de calidad y de búsqueda permanente de la excelencia académica en todas las IES del país, a partir de la implantación e implementación de rigurosos sistemas de autoevaluación, con miras al mejoramiento permanente y al logro de reconocimientos, como la acreditación de programas y de instituciones; esto último, se complementa con el desarrollo de cada uno de los programas que componen el Sistema de Calidad de la Educación Superior, que es, hoy por hoy, el factor que está conduciendo a una mejor cualificación de la Educación Superior y universitaria en Colombia.

En diferentes presentaciones y documentos, el Gobierno Nacional ha venido afirmando que se requiere de una 
reforma, indispensable por todos los cambios del mundo moderno: porque después de 18 años de la Ley 30 , a ella, hay que armonizarla con el presente; porque el número de bachilleres será mayor en un futuro cercano; porque se presenta una significativa deserción supera el $50 \%$; porque se debe lograr una educación superior más pertinente y de mayor calidad; porque es necesario mejorar la cobertura; por la reducida aplicación para recibir acreditación de alta calidad, tanto a nivel de programas como de instituciones y, finalmente, en términos muy sencillos, porque el Grupo de seis países con mayores expectativas de crecimiento y la Organización para la Cooperación y el Desarrollo Económico (OCDE), así lo ordenan.

No dudo que modernizar y actualizar la legislación frente a las realidades de la internacionalización de la Universidad Colombiana es una prioridad $y$, ello, se debe practicar y así como se tienen en cuenta las recomendaciones de la CIVETS y la OCDE, observando sus criterios; es deber igualmente referenciar las redes académicas, tales como: UDUAL, AUALCPI, OUI, IESALC, entre otras y los mandatos de la Conferencia Regional de Educación Superior en Cartagena 2008 y la Conferencia Mundial de Educación Superior en París 2009.

Así se afirme lo contrario, una determinante incuestionable es que está comprobado que las legislaciones únicas para los Sistemas de Educación Superior no son viables. No es factible ni lógico seguir insistiendo que es posible una misma mirada y una misma legislación para las modalidades educativas que, en su fundamento, propósitos y metodologías de formación, tienen, por lógica, consecuencia pedagógica, significativas diferencias. Un concepto es el de UNIVERSIDAD, con objeto de trabajo muy bien establecido y definido y otro, totalmente diferente, en lo que corresponde, a la denominada educación superior (Institutos de educación superior, centros universitarios, institutos técnicos o tecnológicos).

Solo en Colombia, se definen y se aplican criterios comunes para que la docencia, la investigación y la extensión se desarrollen bajo los mismos conceptos, normas y valoraciones académicas en las denominadas IES. No, estas tres funciones sustantivas son patrimonio de lo superior y para lo superior, es decir, para la institución UNIVERSIDAD, que es la entidad que, por su naturaleza, su infraestructura, su organización y sus capacidades organizacionales, lo puede hacer. Cómo vamos a legislar por igual y a exigir de la misma forma a instituciones con responsabilidades tan diferentes?.

No es cierto que las legislaciones en el mundo, actualmente, tengan esa particular mirada de regular un concepto generalista de la Educación Superior. En Europa, caso específico España y demás países, y en América Latina, se legisla para la Universidad y, en forma muy diferente, para las instituciones de Educación Superior. Se pueden medir con el mismo rasero. Es más, me atrevo a decir que, por diversas razones, en Colombia, se hace necesario reglamentar de manera diferente entre universidades de mayor desarrollo relativo y aquellas que están en pleno proceso de crecimiento institucional.

Afirma el Gobierno Nacional que con la reforma a la Ley 30, se pretende: promover la calidad; favorecer el mayor ingreso (mayor cobertura), a partir de un incremento en la oferta; fortalecer la permanencia, superando limitaciones que hoy contribuyen la deserción; adecuar la legislación a nuevas realidades nacionales e internacionales $y$, finalmente, para velar por el buen gobierno y transparencia en el sector y todo ello, supuestamente, favorecido con la inversión privada, con ánimo de lucro en la educación superior, con miras a superar las dificultades de financiamiento, en las denominadas IES.

Favorecer la calidad y la búsqueda permanente de la excelencia académica es una responsabilidad de las propias universidades. Son ellas quienes tienen que definir sus estándares e indicadores de excelencia y lo que le corresponde al Gobierno Nacional es FOMENTAR y FACILITAR estos propósitos; para ello, no se puede estimular la buena práctica sino la gestión y calidad resultaría de fundamental importancia; entonces, legislar sobre aquello, por ejemplo, lo que consagró la Ley 30 para el logro de acreditaciones de programas e instituciones y que no se cumplió, vale la pena analizarlo en sus causas y proponer mecanismos reales y sostenibles en el tiempo.

Reconociendo verdaderamente los procesos de acreditación será posible estimular la investigación y la extensión; aumentar la cobertura, asintiendo y facilitando el ingreso a las universidades de jóvenes provenientes de familias de limitados recursos y de poblaciones vulnerables y, lógicamente, beneficiando su permanencia, de hecho, se soluciona, fortaleciendo la financiación a la demanda y mejorando las condiciones del crédito educativo, pero, igualmente, es importante auspiciar la financiación a la oferta de calidad por parte del gobierno nacional. Evidentemente, el sector privado es una opción y para ello no es necesario invocar principios de lucro, para un servicio que es responsabilidad del Estado y que antes de promover conceptos poco fundamentados, sería importante analizarlo, a partir de las concepciones de Estado, de los actuales legisladores y gobernantes del país. 
La rama legislativa y el Gobierno Nacional no deben tener ninguna limitación para garantizarle a la sociedad colombiana, la transparencia y el buen uso de los recursos económico-financieros, que siempre provienen de la sociedad colombiana, a partir de los impuestos, dinero con el que se financia la Universidad Pública y de las matrículas que son canceladas directamente a las Universidades privadas. Es aquí donde la simple y elemental inspección y vigilancia, que le corresponde al Gobierno Nacional, no debe ahorrar esfuerzos para hacerla verdaderamente viable en aras de legitimar su buen uso a partir de principios de justicia y de equidad para con los usuarios. 